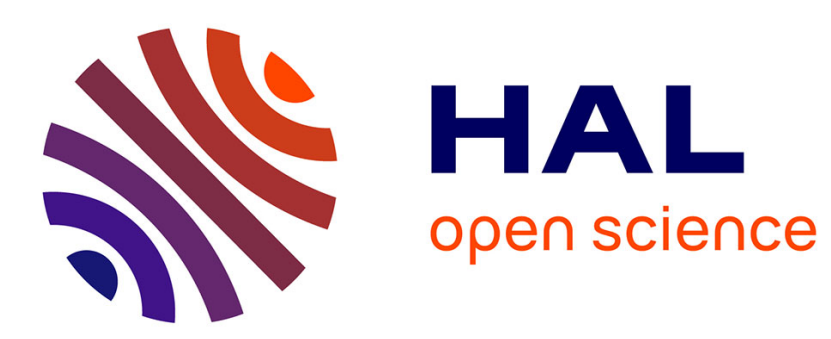

\title{
CMOS RF down-conversion mixer design for low-power wireless communications
}

\author{
Khalid Faitah, Ahmed El Oualkadi, Abdellah Ait Ouhaman
}

\section{To cite this version:}

Khalid Faitah, Ahmed El Oualkadi, Abdellah Ait Ouhaman. CMOS RF down-conversion mixer design for low-power wireless communications. ACM Ubiquity, 2008, 9 (24). hal-00947369

HAL Id: hal-00947369

https://hal.inria.fr/hal-00947369

Submitted on 15 Feb 2014

HAL is a multi-disciplinary open access archive for the deposit and dissemination of scientific research documents, whether they are published or not. The documents may come from teaching and research institutions in France or abroad, or from public or private research centers.
L'archive ouverte pluridisciplinaire HAL, est destinée au dépôt et à la diffusion de documents scientifiques de niveau recherche, publiés ou non, émanant des établissements d'enseignement et de recherche français ou étrangers, des laboratoires publics ou privés. 


\title{
CMOS RF down-conversion mixer design for low-power wireless communications
}

\author{
K. Faitah, A. El Oualkadi, A. Ait Ouahman \\ Laboratoire de Microinformatique, Systèmes Embarqués et Systèmes sur Puces \\ Université Cadi Ayyad. Ecole Nationale des Sciences Appliquées. \\ Avenue Abdelkrim El Khattabi BP : 575 Marrakech Maroc. \\ *Corresponding author.E-mail:faitah@ensa.ac.ma
}

\begin{abstract}
This paper aims to study the design of a low-power single-balanced mixer for downconversion in wireless RF receivers. The proposed circuit is designed to work at a radiofrequency of $1.9 \mathrm{GHz}$ using CMOS $0.18 \mu \mathrm{m}$ technology. The obtained results show a conversion gain equal to $7 \mathrm{~dB}$ and low power consumption of $3.86 \mathrm{~mW}$ at $1.8 \mathrm{~V}$ supply voltage. The single side band noise figure performance was founded to be $8 \mathrm{~dB}$. These results show a good potential of this CMOS mixer and justify its use for low-power wireless communications.
\end{abstract}

Keywords: Analog design, RF mixer, conversion gain, wireless communications, CMOS technology.

\section{Introduction}

The rapid evolution of wireless communication requires increasingly higher performance which raises the complexity of systems used for these applications. This requires the development of new communication systems that will have to meet very strict criteria imposed by this mutation. However, this trend is characterized by a strong demand for new solutions fully integrated with low-cost and low power consumption. Traditionally, wireless systems are built with different technologies, GaAs and SiGe for the radiofrequency part (RF) and CMOS for the baseband part (BB) as shown in Figure 1. The SiGe or GaAs technologies are used for their relatively high transition frequencies and low noise level. However, their manufacturing costs are high. Further more, they are incompatible with the digital building blocks [1].

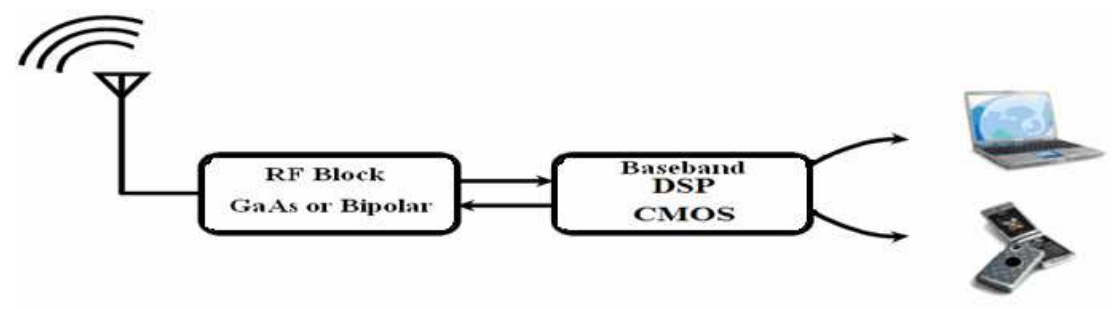

Figure 1 : Bidirectionnel communication system

On the other hand, the use of CMOS technology, to achieve high integration level, has significant advantages for the design of RF integrated circuits. Indeed, in recent years the huge efforts, provided by the microelectronics industry to reduce the size of transistors allow the integration of RF building blocks in CMOS technology. This integration is intended to reduce the cost, the size and the power consumption while increasing the functionality of the system; furthermore, it allows the full integration of both the analog and the digital building blocks on a single chip. Indeed, both the full integration and the low-voltage design, 
particularly in high-frequency applications, require the research and the use of architectures able to pursue the current development of wireless communications systems.

The mixer is an important building block in each communication system whose impact is critical on the performance of other blocks. Indeed, to retrieve the desired signal, it is necessary to perform a frequency conversion by a mixer which allows a time multiplication of two signals, the first one (called RF signal) comes from the receiver antenna after has been filtered and amplified, and the other signal (called LO signal) comes for a local oscillator (Figure 2), the result is a transposition of a high or a low intermediate frequency (IF) with a minimum of a magnitude loss and a minimal noise figure. However, in fact, this conversion process causes a series of difficulties which affect the overall performances of the mixer (gain, noise, linearity, isolation, consumption and cost).

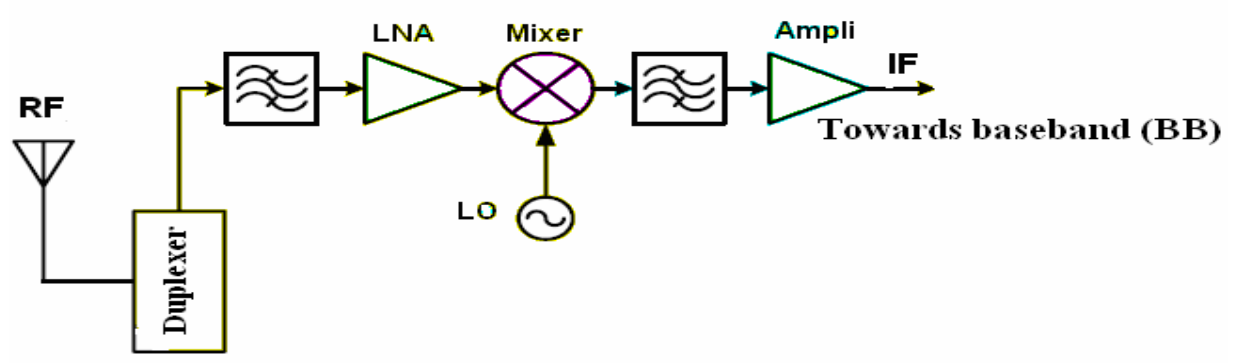

Figure 2 : RF receiver building blocks

This paper aims to study the design of an integrated single-balanced mixer in CMOS $0.18 \mu \mathrm{m}$ for low-power down-conversion in RF reception. The main goal is to optimize the performance of the mixer in order to make it useful for applications in wireless communications around an RF frequency equal to $1.9 \mathrm{GHz}$. To do this, we began our study by searching both the optimal design values of the mixer components in CMOS $0.18 \mu \mathrm{m}$ and the correct bias circuit in order to improve its performance in terms of the conversion gain, the $1-\mathrm{dB}$ compression point and the $3^{\text {rd }}$ order interception point.

\section{Architecture of the proposed mixer}

A mixer is an ideal analog multiplier with three ports. Although the multiplication is a simple mathematical operation, it is difficult (if not impossible) to achieve in an ideal manner [2], since in practice the mixing operation is performed using non-linear components. Also, as shown in figure 2, the mixer is located between a low-noise amplifier (LNA) that receives the RF signal and a channel filter that ensures the signal reception in the desired baseband. Therefore, the choice of CMOS technology in this design is required to ensure both a good gain of the whole system and an excellent matching between the input and output of the mixer circuit.

Figure 3 shows the architecture of the proposed mixer which is a single balanced mixer (SBM). In this design, the RF and LO frequencies are fixed at $1.9 \mathrm{GHz}$ and at $1.8 \mathrm{GHz}$ which offers an intermediate frequency of $100 \mathrm{MHz}$. This IF value can meet the requirements of current communication wireless standards which typically operate around the $1 \mathrm{GHz}$ frequency (such as GSM, IS695, PDC) [3] [4] [5]. 


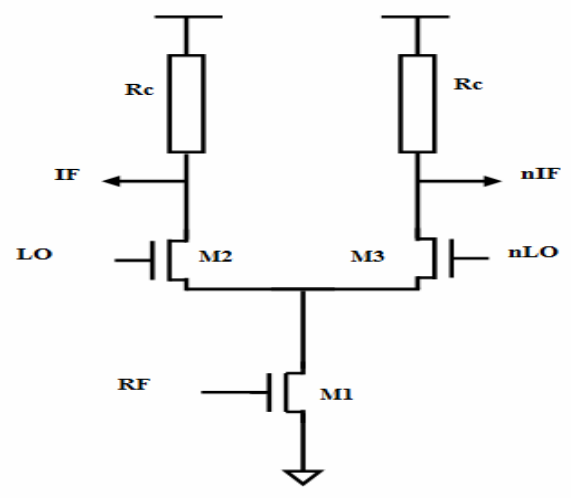

Figure 3 : Architecture of a single balanced mixer

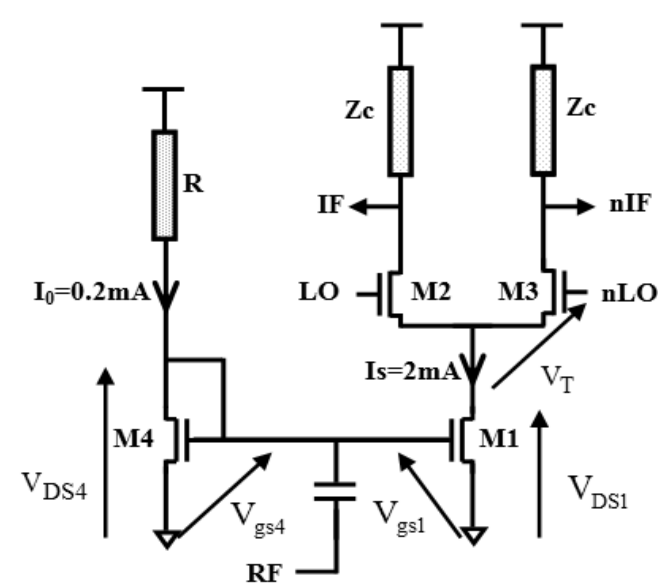

Figure 4 : Biased circuit of the proposed mixer

Moreover, an intermediate frequency of $100 \mathrm{MHz}$ is also very sufficient for cancelling both interferences and problems of image frequency rejection [6], [7].

\section{Mixer circuit design}

\subsection{Bias circuit of the mixer}

Figure 4 shows the biased circuit of the proposed mixer; this circuit can set the static operating point keeping the current mirror transistors $\mathrm{M}_{1}$ and $\mathrm{M}_{4}$ in the saturation mode. We started by looking for the optimal values of $\mathrm{W}$ and $\mathrm{L}$, respectively, the width and length of the NMOS transistors used. Then we run simulations while setting the current $\mathrm{I}_{0}$ to $0.2 \mathrm{~mA}$ with a ratio of 10 between the two NMOS $M_{1}$ and $M_{4}$ to recopy the current $I_{S}(0.2 \times 10=2$ $\mathrm{mA}$ ) by tuning the value of the resistor $\mathrm{R}$ while keeping the voltage $\mathrm{V}_{\mathrm{DD}}=1.8 \mathrm{~V}$.

The relation between $\mathrm{I}_{0}, \mathrm{~V}_{\mathrm{GS}}\left(\mathrm{M}_{4}\right)$ and $\mathrm{V}_{\mathrm{DD}}$ is given by :

$$
\mathrm{I}_{0}=\frac{\mathrm{V}_{\mathrm{DD}}-\mathrm{V}_{\mathrm{GS} 4}}{\mathrm{R}}
$$

At this stage, the effect of channel modulation may arise. Indeed, as shown in figures $5 \mathrm{a}$ and $5 \mathrm{~b}$, for variations in the length $\mathrm{L}$ there is an inverse relationship between the current $\mathrm{I}_{\mathrm{DS}}$ and $\mathrm{V}_{\mathrm{DS}}$ in accordance with the following :

$$
\mathrm{I}_{\mathrm{DS}}=\mu_{\mathrm{n}} \mathrm{C}_{\mathrm{ox}} \frac{\mathrm{W}}{2 \cdot \mathrm{L}}\left[2\left(\mathrm{~V}_{\mathrm{GS}}-\mathrm{V}_{\mathrm{T}}\right) \mathrm{V}_{\mathrm{DS}}-\mathrm{V}_{\mathrm{DS}}{ }^{2}\right]
$$

where $C_{o x}$ is the surface capacity of the grid-channel MOS transistor, $\mathrm{V}_{\mathrm{T}}$ is the threshold voltage and $\mu_{\mathrm{n}}$ is the mobility of carriers.

To solve this issue, the lengths of the $\mathrm{M}_{1}$ and $\mathrm{M}_{4}$ MOS transistors have been increased.

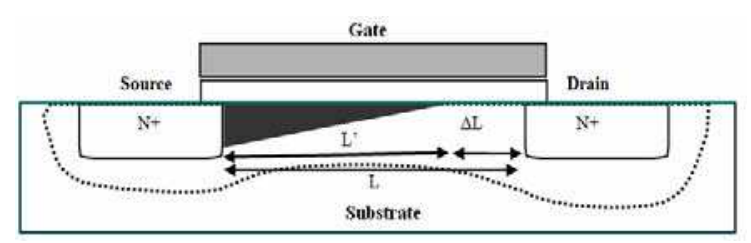

Figure 5.a : MOS transistor

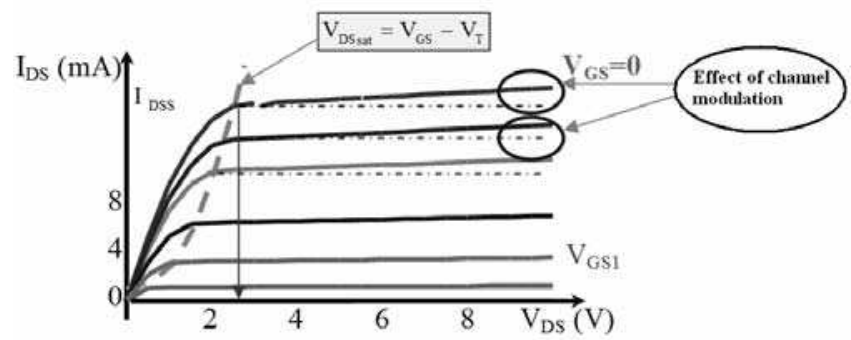

Figure 5.b : Effect of channel modulation 
The saturation condition of transistor $\mathrm{M}_{1}$ is defined by

and as

$$
\mathrm{V}_{\mathrm{DSM} 1}>\left(\mathrm{V}_{\mathrm{GSM} 1}-\mathrm{V}_{\mathrm{T}}\right)
$$

$$
\mathrm{V}_{\mathrm{DCM} 2}=\mathrm{V}_{\mathrm{GSM} 2}+\mathrm{V}_{\mathrm{DSM} 1}
$$

Or $\mathrm{V}_{\mathrm{DCRF}}=\mathrm{V}_{\mathrm{DSM} 1}$ so $\mathrm{V}_{\mathrm{DSM} 1}>\left(\mathrm{V}_{\mathrm{DCRF}}-\mathrm{V}_{\mathrm{T}}\right)$, by replacing (4) in the last inequality, the saturation condition in common mode of LO signal LO becomes

$$
\mathrm{V}_{\mathrm{DCRF}}-\mathrm{V}_{\mathrm{T}}+\mathrm{V}_{\mathrm{GSM} 2}<\mathrm{V}_{\mathrm{DCM} 2}
$$

\subsection{Conversion Gain of the mixer}

The proposed architecture is a single balanced architecture with the two transistors of the differential pair in switching mode; therefore the current output is controlled by the state of the signal generated by the local oscillator which is given by:

$$
\mathrm{I}_{\mathrm{out}}=\mathrm{I}_{\mathrm{S}}(\mathrm{t}) \cdot \operatorname{sign}\left[\mathrm{V}_{\mathrm{LO}}(\mathrm{t})\right]
$$

then, we can obtain

$$
\begin{aligned}
I_{\text {out }}(t) & =\left\{I_{0}+g_{m_{-} r} V_{R F} \cos \left(\omega_{R F} \cdot t\right)\right\} \frac{4}{\pi}\left\{\cos \left(\omega_{O L} \cdot t\right)-\frac{1}{3} \cos \left(3 \omega_{O L} \cdot t\right)+\frac{1}{5} \cos \left(5 \omega_{O L} \cdot t\right)+\ldots\right\} \\
& =\left\{\frac{4 I_{0}}{\pi} \cos \left(\omega_{O L} \cdot t\right)+\frac{2}{\pi} g_{m_{-} r} V_{R F}\left[\cos \left(\left(\omega_{R F}-\omega_{O L}\right) \cdot t\right)-\cos \left(\left(\omega_{R F}+\omega_{O L}\right) \cdot t\right)\right]+\ldots\right\}
\end{aligned}
$$

since

then, we can write

$$
\mathrm{V}_{\text {out }}(t)=\left\{\frac{4 \mathrm{I}_{0}}{\pi} \mathrm{Z}_{\mathrm{c}} \cdot \cos \left(\omega_{\mathrm{OL}} \cdot \mathrm{t}\right)+\frac{2}{\pi} \mathrm{Z}_{\mathrm{c}} \cdot \mathrm{g}_{\mathrm{m}_{-} \mathrm{rf}} \mathrm{V}_{\mathrm{RF}}\left[\cos \left(\left(\omega_{\mathrm{RF}}-\omega_{\mathrm{OL}}\right) \cdot \mathrm{t}\right)-\cos \left(\left(\omega_{\mathrm{RF}}+\omega_{\mathrm{OL}}\right) \cdot \mathrm{t}\right)\right]+\ldots\right\}
$$

where the term $\operatorname{sign}\left[\mathrm{V}_{\mathrm{OL}}(\mathrm{t})\right]=\frac{4}{\pi}\left\{\cos \left(\omega_{\mathrm{OL}} \cdot \mathrm{t}\right)-\frac{1}{3} \cos \left(3 \omega_{\mathrm{OL}} \cdot \mathrm{t}\right)+\frac{1}{5} \cos \left(5 \omega_{\mathrm{OL}} . \mathrm{t}\right) \ldots\right\}$ is the

Fourier transform of a square signal.

We have $I_{s}(t)=I_{0}+g_{m_{-} r} V_{R F} \cos \left(\omega_{R F} \cdot t\right)$.

The conversion gain is given by $\mathrm{G}_{\text {conv }}=\frac{\left|\mathrm{V}_{\text {out }}(\mathrm{t})\right|_{\grave{a}\left(\omega_{\mathrm{RF}}-\omega_{\mathrm{OL}}\right)}}{\left|\mathrm{V}_{\mathrm{RF}}(\mathrm{t})\right|_{\grave{a}\left(\omega_{\mathrm{RF}}\right)}}=\frac{2}{\pi} \mathrm{g}_{\mathrm{m}_{-} \mathrm{rf}} \mathrm{Z}_{\mathrm{c}}$

In a first step, we started the theoretical calculations and simulations using a resistive load $\mathrm{R}_{\mathrm{c}}=\mathrm{Z}_{\mathrm{c}}$, thus:

$$
\mathrm{G}_{\text {conv }}=\frac{2}{\pi} \mathrm{g}_{\mathrm{m}_{-} \mathrm{rf}} \mathrm{R}_{\mathrm{c}}
$$

which yields a theoretical value of $\mathrm{G}_{\text {conv }}=20.12 \mathrm{~dB}$ and simulated $\mathrm{G}_{\text {conv }}=14.39 \mathrm{~dB}$.

This difference between the two gains requires taking into account the resistance of the differential pair $r_{D S}$ which is in parallel with $R_{c}$, the gain relationship becomes then:

$$
\mathrm{G}_{\mathrm{conv}}=\frac{2}{\pi} \mathrm{g}_{\mathrm{m}}\left(\mathrm{R}_{\mathrm{c}} / / \mathrm{r}_{\mathrm{DS}}\right)
$$

and in this case we found :

Theoretical $\mathrm{G}_{\mathrm{conv}}=14.43 \mathrm{~dB}$ and simulated $\mathrm{G}_{\mathrm{conv}}=14.39 \mathrm{~dB}$.

This simulation shows the importance of taking into account all the parameters that could affect the results.

Note that the differential output generates a signal containing two other frequencies:

$f_{R F}-f_{L O}$ et $f_{R F}+f_{L O}$ hence the need to use a capacitor $C$ to filter the HF $: f_{R F}+f_{L O}$. The gain relationship becomes then: 


$$
\mathrm{G}_{\mathrm{conv}}=\frac{2}{\pi} \mathrm{g}_{\mathrm{m}}\left(\mathrm{R}_{\mathrm{c}} / / \mathrm{r}_{\mathrm{DS}} / / \mathrm{C}\right)
$$

this gives: theoretical $\mathrm{G}_{\mathrm{conv}}=7.2 \mathrm{~dB}$ and simulated $\mathrm{G}_{\mathrm{conv}}=7.4 \mathrm{~dB}$.

Certainly adding this capacity decreases the performances of the mixer in terms of voltage gain, but it helps to have a good filtered output signal.

\section{Performances of the mixer design}

As mentioned above, the conversion gain depends mainly on the bias resistor Rc as shown in the following table:

\begin{tabular}{|c|c|c|}
\hline Rc ( $\mathbf{\Omega})$ & Conv Gain (dB) & NF (dB) \\
\hline 200 & 7 & $\mathbf{8}$ \\
\hline 400 & 4 & 9 \\
\hline 100 & 3 & 8 \\
\hline
\end{tabular}

Table 1 : Variation of the conversion gain \& the noise factor with $R_{c}$ values

The conversion gain and the noise factor are optimal for a value of $\mathrm{Rc}=200 \Omega$. This is found with the following sizes of NMOS used:

$\mathrm{L}=0.18 \mu \mathrm{m}$ : Gate length of all transistors.

$\mathrm{W}=100 \mu \mathrm{m}$ : Gate width of $\mathrm{M}_{1}, \mathrm{M}_{2}, \mathrm{M}_{3}$ and $\mathrm{W}_{4}=80 \mu \mathrm{m}$ Gate width of $\mathrm{M}_{4}$.

A DC simulation, using the values mentioned above, can provide the power consumption of $3.86 \mathrm{~mW}\left(\mathrm{~V}_{\mathrm{DD}}=1.8 \mathrm{~V}\right.$ and $\left.\mathrm{I}_{\mathrm{S}}=2.145 \mathrm{~mA}\right)$.

\section{- Results of transient simulation:}

Figure 6 shows the IF output signal whose frequency is about $100 \mathrm{MHz}$, such an output signal is in fact the modulation of the carrier RF and the IF signal that can be obtained after a proper filtering of other frequency harmonics.

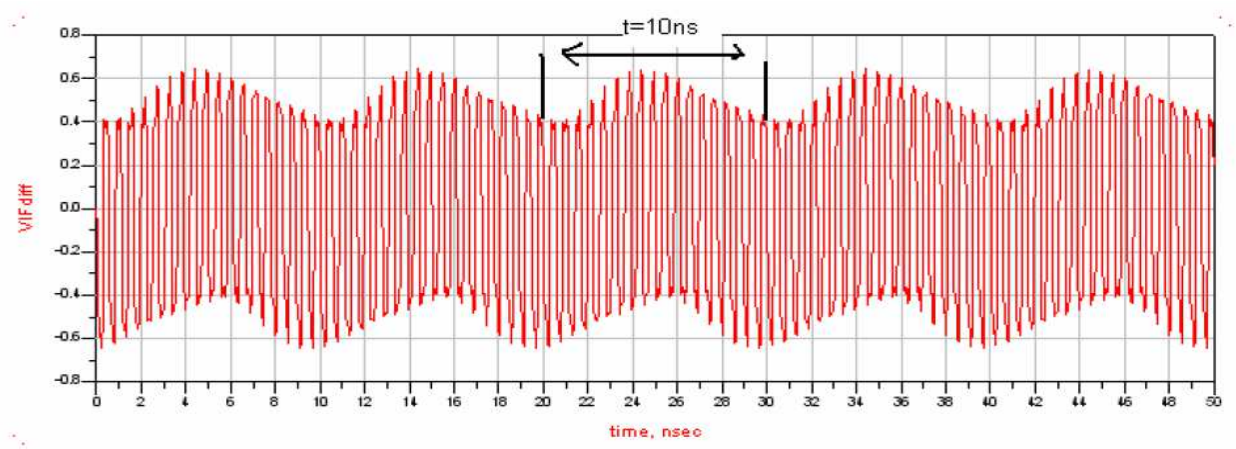

Figure 6 : IF output signal as a function of time.

\section{- Results in the frequency domain:}

Figure 7 shows a linear region where the output power is directly proportional to the input power and a decreasing region from $-10 \mathrm{dBm}$ resulted in the non-linearity of the mixer circuit. These results are obtained by tuning the input power from $-50 \mathrm{dBm}$ to $0 \mathrm{dBm}$. 


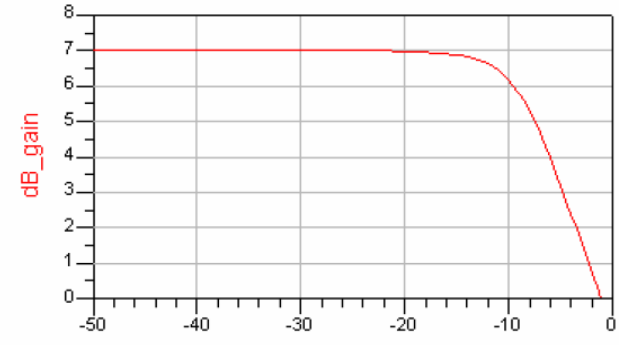

Figure 7 : Gain versus RF input power

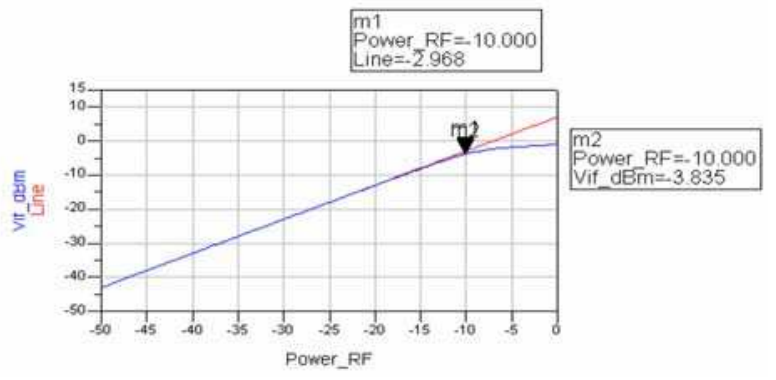

Figure 8 : 1-dB compression point

Figure 8 shows the simulation of $1-\mathrm{dB}$ compression point which is equal to $-10 \mathrm{dBm}$. To evaluate the distortion in the mixer circuit, the third input intercept point (IIP3) was simulated. From figure 9, the resulted IIP3 is roughly equal to $-5 \mathrm{dBm}$, indeed by considering the input signals : $\mathrm{fl}=1.8 \mathrm{GHz}$ and $2 . \mathrm{f1}-\mathrm{f} 2=1.7 \mathrm{GHz}$, and an input power equal to -10 $\mathrm{dBm}$, then :

$$
I I P 3=\frac{I M 3}{2}+\text { Power_RF }[8] \quad I I P 3=\frac{10,7}{2}-10 \approx-5 \mathrm{dBm}
$$

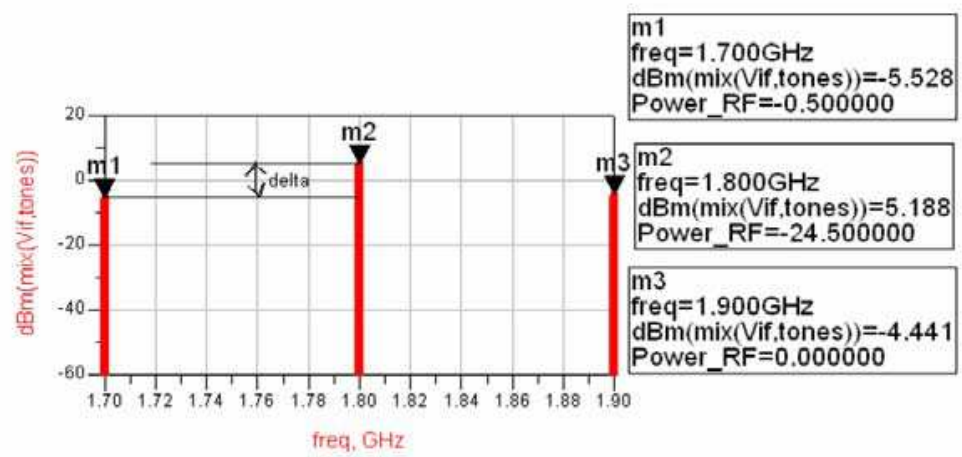

Figure 9 : Third order input intercept point (IIP3)

The performances of the proposed mixer are compared with the state-of-the-art (table 2). It seems that proposed design shows good performances in term of conversion gain and power consumption value, compared to other previously reported designs. However, the IIP3 and the 1-dB compression points are still at a reasonable level.

\begin{tabular}{|c|c|c|c|c|c|c|c|c|}
\hline Ref & $\begin{array}{l}\text { Supply } \\
\text { Voltage } \\
\text { (Volts) }\end{array}$ & $\begin{array}{l}\text { Freq. } \\
\text { RF } \\
\text { (GHz) }\end{array}$ & $\begin{array}{c}\text { CG } \\
\text { [dB] }\end{array}$ & $\begin{array}{c}\text { IIP }_{3} \\
\left(\mathbf{d B m}^{\prime}\right)\end{array}$ & $\begin{array}{c}\text { P-1dB } \\
\text { (dBm } \\
\text { ) }\end{array}$ & $\begin{array}{c}\text { Noise } \\
\text { Figure } \\
\text { (dB) }\end{array}$ & $\begin{array}{l}\text { Tech. } \\
(\mu \mathrm{m})\end{array}$ & $\begin{array}{c}\text { Power } \\
\text { Consum.(m } \\
\text { W) }\end{array}$ \\
\hline [9] & 2 & 0.9 & 1.1 & -3.3 & -15.4 & - & 0.35 & 7.2 \\
\hline [10] & 1.5 & 2.4 & $3 \cdot 3$ & 5.46 & -8.98 & 14.87 & 0.18 & 5.6 \\
\hline [11] & 1.8 & 2.44 & -2.6 & 12.81 & 5.07 & 13.67 & 0.25 & 13.3 \\
\hline [12] & 1.8 & $\begin{array}{l}3.168- \\
3.693\end{array}$ & $7 \cdot 5^{-10.1}$ & - & - & $8.8-12.5$ & & 13.24 \\
\hline$\frac{\text { This }}{\text { work }}$ & 1.8 & 1.9 & 7 & -5 & -10 & 8 & 0.18 & 3.8 \\
\hline
\end{tabular}

Table 2: Performance Comparison of recent mixers 


\section{Conclusion:}

The proposed study has demonstrated the design of a low power single balanced mixer in CMOS $0.18 \mu \mathrm{m}$ technology. The designed mixer shows a suitable gain when considering that the supply voltage does not exceed $1.8 \mathrm{~V}$ with a very low power consumption of $3.8 \mathrm{~mW}$, a noise figure of $8 \mathrm{~dB}$, a $1-\mathrm{dB}$ compression point of $-10 \mathrm{dBm}$ and an IIP 3 of $-5 \mathrm{dBm}$. These performances allow both a low-size and a low-cost integration of the proposed mixer on a single chip which makes this design very suitable for low-power wireless communication applications in the band around a RF frequency of $1.9 \mathrm{GHz}$.

[1] A. Pärssinen, J. Jussila, J. Ryynänen, L. Sumanen, K. Kivekäs and K. Halonen, "Circuit Solutions for WCDMA Direct Conversion Receiver", IEEE Norsig 2000, Kolmärden, Sweden, June 13-15, 2000.

[2] Abidi A.A., "High frequency noise measurements on FETs with small Dimensions," IEEE Trans. on Electron Devices, vol.ED-33, Nov 1986.

[3] Coffing D., Main E., "Effects of offsets on bipolar integrated circuit mixer even-order distortion terms," IEEE Trans. Microwave Theory Tech., vol.49, pp.23-30, 2001.

[4] Proakis J.G., Digital communications, Mc Graw Hill, New York, 905 pages, 1989.

[5] Razavi B., "Design considerations for direct conversion receivers," IEEE Transactions on Circuits and Systems-II, Analog and Digital Signal Processing, vol.44, pp.428-435, 1997.

[6] J. Auvray ''Electronique des signaux analogiques' Edition Dunod, p: 338 - 339, 1980.

[7] T. Chouchane, M. Sawan, "A 5 GHz CMOS RF Mixer in $0.18 \mu \mathrm{m}$ CMOS Technology," IEEE CCECE 2003, Montreal, May 2003.

[8] D. Leenaerts, J. Van der Tang, Cicero S. Vaucher, Circuit Design for RF Transceivers, KLUWER ACADEMIC PUBLISHERS, 2001, pp : 122 - 128.

[9] C.F Au-Yeung and K.K.M.Cheng, "CMOS mixer Linearization by the low frequency signal injection method," IEEE MTT-S International Microwave Symposium Digest, vol 1,pp.95-98, June 2003.

[10] Hung-Che Wei, Ro-Min Weng, Chih-Lung Hsiaoand Kun-Yi Lin, " A 1.5V 2.4GHz CMOS \Mixer With High Linearity", The 2004 IEEE Asia-Pacific Conference Circuit and Systems,Dec 6-9, 2004.

[11] Kumar Munusamy and Zubaida Yusoff "A Highly Linear CMOS Down Conversion Double Balanced Mixer” ICSE 2006 Proc. 2006, Kuala Lumpur, Malaysia pp 985-990.

[12] Goo-Young Jung, Jae-Hoon Shin, Tae-eoul Yun " A low noise UWB cmos mixer using current bleeding and resonant inductor techniques. Wiley InterScience Journal, Volume 49, pp. 1595 - 1597. April 2007 